\title{
AN INTERESTING CASE OF GASTRIC VOLVULUS
}

Suraj Subramaniam S1, Vijay Sampath², Rohini Jayashankar³, Mohamed Mustafa4, M. Baskaran Selvapathy 5

\section{HOW TO CITE THIS ARTICLE:}

Suraj Subramaniam S, Vijay Sampath, Rohini Jayashankar, Mohamed Mustafa, M. Baskaran Selvapathy. "An Interesting Case of Gastric Volvulus". Journal of Evolution of Medical and Dental Sciences 2014; Vol. 3, Issue 17, April 28; Page: 4605-4607, DOI: 10.14260/jemds/2014/2483

INTRODUCTION: Gastric volvulus as a clinical entity is less common in occurrence. We report a rare case of gastric volvulus with spontaneous resolution, which was successfully treated with laparoscopic gastropexy to avoid further recurrences.

AIM \& OBJECTIVE: To present a less common entity, managed by minimally invasive procedure.

CASE HISTORY, MANAGEMENT AND FOLLOW UP REPORT: A 16 year young thin built girl, presented with sudden onset of (<5 HRS) massive upper abdominal distension and abdominal pain. There is no past history of similar episode. After few initial failed attempts to insert a naso gastric tube, patient had sudden bout of vomiting in the A and E department which resulted in partial reduction of the abdominal distension. The vomitus was non-bilious and contained food particles. After initial stabilization of patient with IV fluids, antiemetics and other supportive measure, USG abdomen revealed rotation of stomach with features suggestive of Gastric volvulus. CT abdomen demonstrated gross gastric distension, no extraneous gastric outlet or duodenal compression/ obstruction. Since the patient developed sudden bout of vomiting which followed by resolution of abdominal distension, the possibility of gastric volvulus with spontaneous resolution was thought about. Since the patient showed signs of recovery after the vomiting episode, it was planned to managed conservatively initially with close monitoring of the general condition and vital signs. Patient also showed complete recovery on the following day with abdominal distension disappearing completely. The upper GI scope on that day revealed a grossly distended stomach with no gastric outlet obstruction. The scope was entered up to the second part of duodenum. She was started on oral diet on the third day of admission. She tolerated the oral diet well without any episode of vomiting or abdominal distension. The partial gastric volvulus has high chance of recurrence. Hence the possibility of similar episode in future for this patient was thought about. Thus a diagnostic laparoscopy was done which revealed a grossly enlarged stomach with no evidence of any diaphragmatic defect. And hence Laparoscopic gastropexy was performed as a definitive procedure. Post-operative period was uneventful. She was started oral feeds on $2^{\text {nd }}$ post-operative day. Patient was discharged on $4^{\text {th }}$ post-operative day. Sutures were removed on $10^{\text {th }}$ post-operative day. On five months of follow up no similar episode was reported by her. Patient is kept on further follow up. 


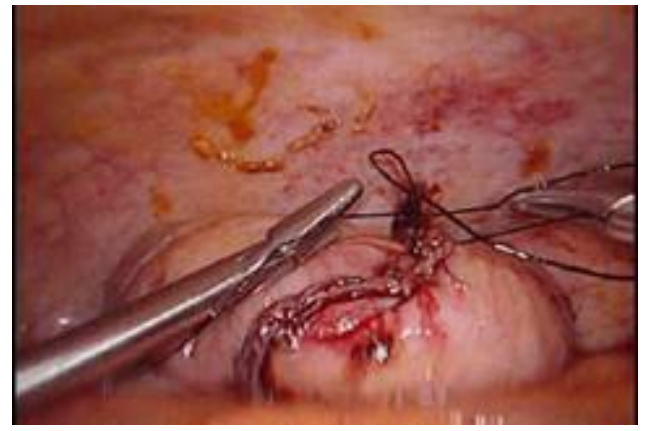

\section{Laparoscopic Gastropexy being done}

\section{Review of literature:}

Etiology: Most commonly the gastric volvulus is associated with diaphragmatic defect secondary to trauma and paraoesophageal hernia. In children it is said to occur with congenital defect such as the foramen of Bochdalek or eventration. ${ }^{1}$

Types of gastric volvulus: Organoaxial and mesenteroaxial.

Symptoms of gastric Volvulus: Sudden onset of abdominal pain, abdominal distension, vomiting and upper GI bleeding. The presence of upper abdominal pain with inability to pass Ryle's tube and recurrent retching with little vomitus is called as Bochardt's triad.

Complication of gastric volvulus: Acute GV usually presents with progressive abdominal (intraabdominal volvulus) or chest (intra-thoracic volvulus) pain, severe vomiting, and epigastric distention. Acute GV can lead to strangulation, necrosis and perforation of the stomach, and should be regarded as a surgical emergency ${ }^{2}$. The incidence of strangulation rate in gastric volvulus is about $5-28 \%$.

Recurrent gastric Volvulus: In contrast, chronic gastric volvulus might be completely asymptomatic or manifest with recurrent non-specific symptoms such as vague abdominal pain, abdominal fullness, chest pain, retching, acid reflux, and dysphagia. The natural history of chronic gastric volvulus remains poorly understood. Although theoretically chronic GV can transform into acute volvulus, the actual incidence is unknown ${ }^{3,4}$. The mesenteroaxial volvulus with $<180$ degrees rotation has high incident of recurrence ${ }^{1}$.

CONCLUSION: We present this case to highlight the rarity of occurrence of this clinical entity and its successful laparoscopic management. The gastric volvulus has high mortality and morbidity rate when presenting with strangulation and gangrenous stomach. This condition has also got possibility of recurrence. Hence in our patient to prevent possible future recurrent volvulus and life threatening complications like strangulation laparoscopic gastropexy was done as a definitive treatment option.

\section{REFERENCES:}

1. Mercer DW, Robinson EK (2008). Stomach in Sabisten Textbook of Surgery Volume 2 (pp 12731274). Philadelphia, PA: Elsevier.

2. Wasselle JA, Norman J. Acute gastric volvulus: pathogenesis, diagnosis, and treatment. Am J Gastroenterol. 1993; 88:1780-1784. 


\section{CASE REPORT}

3. Patel NM. Chronic gastric volvulus: report of a case and review of literature. Am J Gastroenterol. 1985; 80:170-173.

4. Shivanand G, et al Gastric volvulus: acute and chronic presentation. Clin Imaging. 2003; 27:265268.

\section{AUTHORS:}

1. Suraj Subramaniam S

2. Vijay Sampath

3. Rohini Jayashankar

4. Mohamed Mustafa

5. M. Baskaran Selvapathy

\section{PARTICULARS OF CONTRIBUTORS:}

1. Associate Professor, Department of General Surgery, SRM Medical College Hospital and Research Centre.

2. Assistant Professor, Department of General Surgery, SRM Medical College Hospital and Research Centre.

3. Assistant Professor, Department of General Surgery, SRM Medical College Hospital and Research Centre.

4. Professor, Department of General Surgery, SRM Medical College Hospital and Research Centre.
5. Professor, Department of General Surgery, SRM Medical College Hospital and Research Centre.

\section{NAME ADDRESS EMAIL ID OF THE CORRESPONDING AUTHOR:}

Dr. Vijay S,

Department of General Surgery, SRM Medical College Hospital and Research Centre, SRM Nagar, Potheri, Kancheepuram - 603203.

E-mail: drvijay06@hotmail.com

Date of Submission: 01/04/2014. Date of Peer Review: 02/04/2014. Date of Acceptance: 15/04/2014. Date of Publishing: 25/04/2014. 